\title{
Caracterización Espectral y Detección de Flecha Seca en Palma Africana en Puntarenas, Costa Rica ${ }^{1}$
}

\author{
Spectral Characterization and Detection of Bud Rot on Oil \\ Palm in Puntarenas, Costa Rica
}

\author{
Rubén Martínez-Barbáchano ${ }^{2}$ \\ Universidad de Costa Rica, Costa Rica \\ Gustavo Adolfo Solís-Miranda \\ Universidad Nacional, Costa Rica
}

http://dx.doi.org/10.15359/rgac.61-2.13

\section{RESUMEN}

La agricultura de precisión en las últimas décadas ha visto notables avances técnicos que han permitido un mejor manejo de las explotaciones agrícolas, optimizando recursos e insumos aplicados. En el ámbito de la geomática, los sensores ópticos terrestres han permitido profundizar y ampliar el conocimiento del comportamiento espectral de los cultivos en estudio, con beneficios cada vez mayores en aplicación de tratamientos y prevención de enfermedades y/o plagas. El objetivo de este trabajo fue caracterizar la palma africana (Elaeis guineensis jacq.) por medio de espectro-radiometría de campo, en plantas sanas y afectadas por la flecha seca. El estudio se efectuó entre marzo y mayo de 2016 en fincas de palma africana, ubicadas en Parrita de Puntarenas, Costa Rica. Se utilizó un sensor terrestre hiperespectral con un rango de longitud de onda abarcado de 325 a 1075 nanómetros (espectro visible e infrarrojo cercano). En general, las plantas en condición

1 Este trabajo formó parte del Trabajo Final de Graduación de ambos para optar por el grado de Máster en Sistemas de Información Geográfica y Teledetección. Universidad de Costa Rica / Universidad Nacional de Costa Rica.

2 Universidad de Costa Rica, San José, Costa Rica. Correo electrónico: ruben.martinezbarbachano@ucr.ac.cr

3 Universidad de Costa Rica - Universidad Nacional de Costa Rica, Costa Rica. Correo electrónico: gasolism@gmail.com

Fecha de recepción: 7 de diciembre de 2017

Fecha de aceptación: 19 de marzo de 2018 
fitosanitaria sana, que además tuvieron un tratamiento de "fertilización+riego", presentaron las curvas de reflectividad más elevadas, en torno a un $0,7 \%$. La influencia por flecha seca en la curva de reflectancia de las plantas tuvo un mayor peso, en la mayoría de los casos, que el tipo de tratamiento al que están sometidas. Se confirma así la posibilidad de detectar la patología de flecha seca mediante espectroscopía de reflectancia en condiciones de trabajo de campo, objetivo principal de la presente investigación.

Palabras clave: Espectroscopía, teledetección, infrarrojo, reflectancia

\begin{abstract}
During the last decades, precision agriculture has observed significant technical progress that has permitted better management of farming, optimizing resources and applied inputs. Within the scope of geomatics, land optical sensors have allowed to expand and increase knowledge on the spectral behavior of the crops under study, providing increased benefits in the application of treatments and pest or disease prevention. The objective of this work was to characterize the African oil palm (Elaeis guineensis Jacq.), by means of field radiometry-spectrum, in healthy plants, as well as in plants affected by bud rot. The study was conducted between March and May 2016 in African oil palm farms in Parrita, Puntarenas, Costa Rica. A hyperspectral land sensor, with a 325-1075 nm wavelength range (visible and near-infrared spectrum), was used. In general, plants in healthy phytosanitary condition, which also had a treatment of "fertilization+irrigation", presented the highest reflectivity curves: around $0.7 \%$. The bud rot influence in the reflectance curve of the plants had, in most cases, a greater weight than the type of treatment to which they are subjected. It thus confirms the possibility of detecting the bud rot pathology through reflectance spectroscopy in conditions of field work, the main goal of this research.
\end{abstract}

Keywords: Spectroscopy, near infrared, reflectance, land optical sensors.

\title{
Introducción
}

Los sensores remotos y la teledetección aplicados a la gestión de los recursos naturales y el ordenamiento territorial, se sirven de la respuesta obtenida en el espectro electromagnético de las diferentes coberturas (cultivos en este caso). Enfermedades y plagas generan estrés fisiológico y cambios físicos en los cultivos. Dichos cambios producen alteraciones en las propiedades reflectantes del cultivo, observables en su firma espectral. Se trata de una técnica utilizada desde hace mucho tiempo en diferentes campos de la química, para caracterizar las propiedades de diferentes tipos de muestras. Las ventajas demostradas en los últimos años no solamente se relacionan con la precisión de sus determinaciones, sino también con la rapidez en que se hacen (Bloemberger et al., 2007).

La palma africana (Elaeis guineensis) es probablemente el cultivo más importante en la Zona Sur del Pacífico de Costa Rica. Genera más de 8000 empleos directos permanentes durante todo el año, además de unos 31000 indirectos. La vigilancia y el control de plagas que afectan a esta 
Rubén Martínez-Barbáchano, Gustavo Adolfo Solis-Miranda. Caracterización Espectral y Detección de Flecha Seca en Palma Africana en Puntarenas, Costa Rica

especie de elevado interés agronómico ha motivado el planteamiento de estrategias técnicas y de coordinación para un manejo integrado del cultivo (MAG, 2007). La "Flecha Seca" o pudrición del cogollo, es una enfermedad que está afectando severamente a la producción de este cultivo, y que ha motivado la aparición de propuestas metodológicas de estudio y prevención de dicha patología, evaluando diversas prácticas agronómicas para mejorar el control sobre la misma.

La pudrición de la flecha y del cogollo son conocidos en Colombia, en el Ecuador (tanto en la vertiente pacífica como en la parte amazónica), en el Perú, en Brasil y en el Pacífico Central y Sur de Costa Rica. El problema se planteó por primera vez en gran escala en 1967, en una plantación comercial en Turbo, en Colombia.

El amarillamiento y el secamiento ocasionado por la flecha son imperceptibles, y en cuanto aparecen estos primeros síntomas de clorosis, la base de las hojas muy jóvenes ya está podrida e invadida por larvas de insectos, bajando profundamente esta pudrición hasta el meristemo, como se aprecia en la figura 1 (Quesada, 2010).

Figura 1. Ejemplar de palma africana (Elaeis guineensis) severamente afectada por flecha seca en Parrita, Puntarenas, Costa Rica.

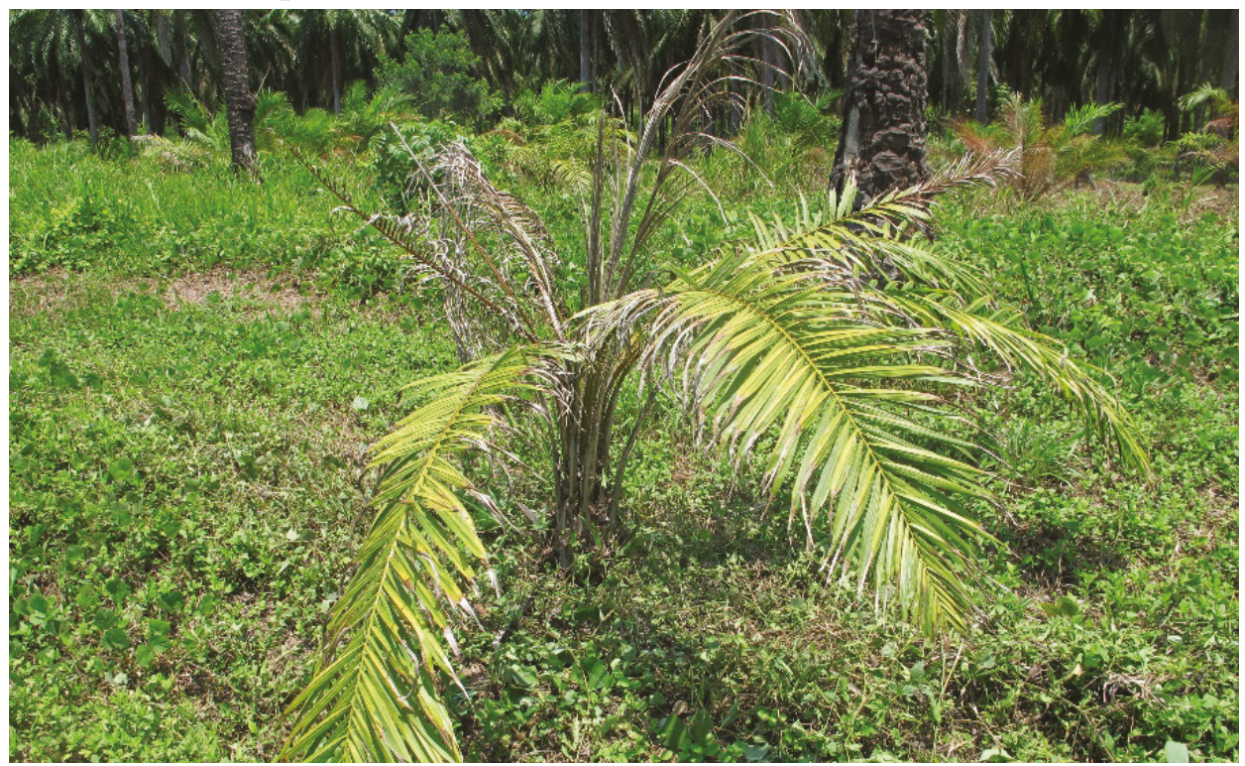

Fuente: Quesada, 2010. 
A consecuencia de esta pudrición, una o varias flechas se doblan. En estados avanzados, la pudrición se extiende al meristema apical, bases peciolares y primordios florales (Rivas-Figueroa, 2015).

Los diferentes tipos de cultivo presentan una firma espectral típica, relacionada con características como la fisiología, la estructura del cultivo (geometría) o el tratamiento al que está sometido, entre otras. La proporción de luz incidente que es reflejada, absorbida o transmitida depende de las características de la cobertura del suelo y de la longitud de onda. La firma espectral de un cultivo está condicionada por la presencia de pigmentos, la estructura de la hoja y su contenido en humedad. (ChuviecoSalinero, 2010)

La espectro-radiometría de campo es básicamente una estimación cuantitativa o medida de radiancia, irradiancia o reflectividad en el campo, es decir, en condiciones de iluminación natural. El desarrollo de esta técnica ha estado muy ligado al de las plataformas aeroespaciales. Es a partir de las décadas de 1960 y 1970, cuando estas tecnologías cobran mayor relevancia, especialmente, cuando se percibe la importancia de obtener medidas precisas en la región del SWIR (infrarrojo medio de onda corta) entre 1100 y 2400 nanómetros, debido a que se descubrió todo el potencial que estas longitudes de onda tenían en el campo de las aplicaciones geológicas (Goetz, Vane, Solomon, Rock, 1985)

El papel que la espectro-radiometría juega en el campo de los sensores remotos viene dado por la ayuda que brinda a la hora de cubrir ciertas limitaciones habituales en teledetección, como son:

- $\quad$ La resolución espectral; ya que en espectroscopía se puede elegir la anchura y localización óptima de las bandas para detectar y caracterizar un objeto o cubierta determinada.

- La resolución espacial requerida para el estudio del fenómeno, ya que se pueden escoger las dimensiones de la superficie o cubierta muestreada.

- Mejor período del año y momento del día para analizar una variable. - Cuál es la variabilidad espacial y espectral de un objeto o cubierta.

La base fundamental de la espectroscopía es que la radiación sufre modificaciones observables y medibles al interactuar con determinadas coberturas, lo cual depende de su composición química y de sus atributos 
Rubén Martínez-Barbáchano, Gustavo Adolfo Solis-Miranda. Caracterización Espectral y Detección de Flecha Seca en Palma Africana en Puntarenas, Costa Rica

físicos/estructurales. Respecto a la composición química, se afirma que la luz incidente en los objetos causa vibración en las moléculas, las cuales absorben energía asociada a una longitud de onda determinada, y refleja otras. Así, se puede estimar la cantidad de unas y otras moléculas (absorbidas, transmitidas o reflejadas) presentes en el objeto o muestra (Botero, 2009).

La espectroscopía de reflectancia proporciona un método alternativo a los análisis de vegetación y suelos, con un elevado número de investigaciones desarrolladas en este campo. Existen estudios que han determinado el contenido de carbono orgánico en el suelo, encontrando, que los espectrómetros de laboratorio y portátiles de campo presentan precisiones similares cuando las condiciones de campo son de poca variabilidad (rugosidad, humedad superficial del suelo y ausencia de vegetación), mientras que los sensores aéreos no presentan condiciones aceptables de precisión en la determinación de este parámetro. Se ha verificado que los sensores espectrales de laboratorio y campo dan estimaciones con precisiones similares a las que brindan los análisis de laboratorio de rutina como el método de Walkley y Black. De hecho, ya se han montado sensores de este tipo sobre tractores como insumo para procesos de agricultura de precisión, y para el mapeo de diferentes características de suelo y cultivos (Stevens et al., 1990).

La reflexión es la forma más importante de la teledetección, y se deriva directamente de la luz solar, principal fuente de iluminación del planeta. El sol ilumina la superficie terrestre y ésta refleja esa energía en función del tipo de cubierta presente sobre ella. Posteriormente, este flujo de energía reflejado es recogido por el sensor, pero entre la superficie y el sensor se interpone la atmósfera que dispersa y absorbe parte de la energía original (Campbell, 2002).

La radiación infrarroja, que comprende el rango del espectro electromagnético entre $780 \mathrm{~nm}$ y 2500 nanómetros, fue descubierta por Friedric Wilhelm Herschel en el año 1800. La primera vez que se utilizó espectroscopía de Infrarrojo Cercano fue en la agricultura, en 1964, para determinar el contenido de humedad de los cereales, desde entonces se viene utilizando en la determinación de humedad, proteína y grasa, cantidad de sólidos solubles y cantidad de materia seca en diversos alimentos y productos agrícolas, y más recientemente, con sensores ópticos terrestres. En un principio, se utilizaron para que la aplicación del nitrógeno en cereales se realizase de una manera más racional y eficiente. En las grandes extensiones de cereal de 
algunos países, uno de los factores más importantes en la producción es el aporte de nitrógeno, tanto por su correlación directa con la cantidad producida, como por su elevado precio (Botero, 2009).

En el espectro visible (es decir, en el azul/verde/rojo) el comportamiento diferencial de los objetos en distintas longitudes de onda da lugar al color. Por ejemplo, un color azul es así porque refleja una elevada cantidad de energía en esa banda del espectro, y poca en el resto de bandas. O, dicho de otro modo, si absorbe o transmite escasa energía incidente en esa longitud de onda refleja una elevada cantidad en el azul (de 420 a $520 \mathrm{~nm}$ ) por lo cual, el color observado es azul (Chuvieco-Salinero, 2010).

A partir de medidas de laboratorio, se han podido elaborar curvas de reflectividad espectral para las principales cubiertas terrestres. Algunas de estas tienden a presentar una respuesta uniforme en diferentes longitudes de onda, mientras que otras ofrecen un comportamiento más selectivo (Chuvieco-Salinero, 2010):

- $\quad$ El agua absorbe la mayor parte de la energía que recibe, y este porcentaje es mayor cuanto mayor es la longitud de onda (cuanto más absorbe, menos refleja).

- La vegetación es un caso particular, pues tiene un comportamiento muy cromático. Posee valores bajos de reflectividad en el espectro visible (de 0,4 a $0,7 \mu \mathrm{m}$ ), pero suben en el infrarrojo próximo, y vuelven a decrecer en torno al infrarrojo medio.

Junto a esto, que se denominan firmas espectrales, hay que tomar en cuenta que el flujo de energía que recibe el sensor va a depender no solo de la receptividad del mismo, sino de factores externos como:

- Las condiciones atmosféricas que afectan la energía que absorben las nubes y la dispersión selectiva en algunas longitudes de onda.

- $\quad$ Tipo de sustrato, fundamentalmente litológico o edáfico, sobre el cual se está observando.

- Geometría de la observación (fundamentalmente rugosidad y textura de la cubierta observada).

- Modificación que el relieve introduce en el ángulo de observación (orientación de laderas y pendientes). 
En cualquier caso, el ángulo de elevación del sol y el de observación desempeñarán un papel destacado en la respuesta, finalmente, obtenida por el sensor. Esto significa que un mismo sensor puede recibir valores diferentes de radiancia espectral para una misma cubierta si varían las condiciones de observación o iluminación. De hecho, el comportamiento de una cubierta en el espectro visible está definido no solo por sus características intrínsecas, sino también por factores externos:

- $\quad$ Ángulo de iluminación solar, que dependerá de la fecha del año.

- Modificación que el relieve introduce en el ángulo de observación (orientación de laderas y pendientes).

- Influencia de la atmósfera, principalmente, en energía que absorben las nubes y dispersión selectiva en algunas longitudes de onda (Figura 2).

- Variaciones medioambientales de la cubierta observada (estación o época para la vegetación, grado de homogeneidad de las masas, etc.).

- $\quad$ Naturaleza del sustrato sobre el cual se está observando.

Por tanto, en torno a un comportamiento tipo de una determinada cubierta terrestre (o signatura espectral) existe una cierta variabilidad, que depende de los factores externos anteriormente citados. La reflectividad del suelo desnudo, no obstante, presenta notables diferencias, especialmente entre suelos secos (como el asfalto) y húmedos (aluviales) como se muestra en la Figura 2. 
Figura 2. Signaturas espectrales de cuatro cubiertas habituales en Teledetección.

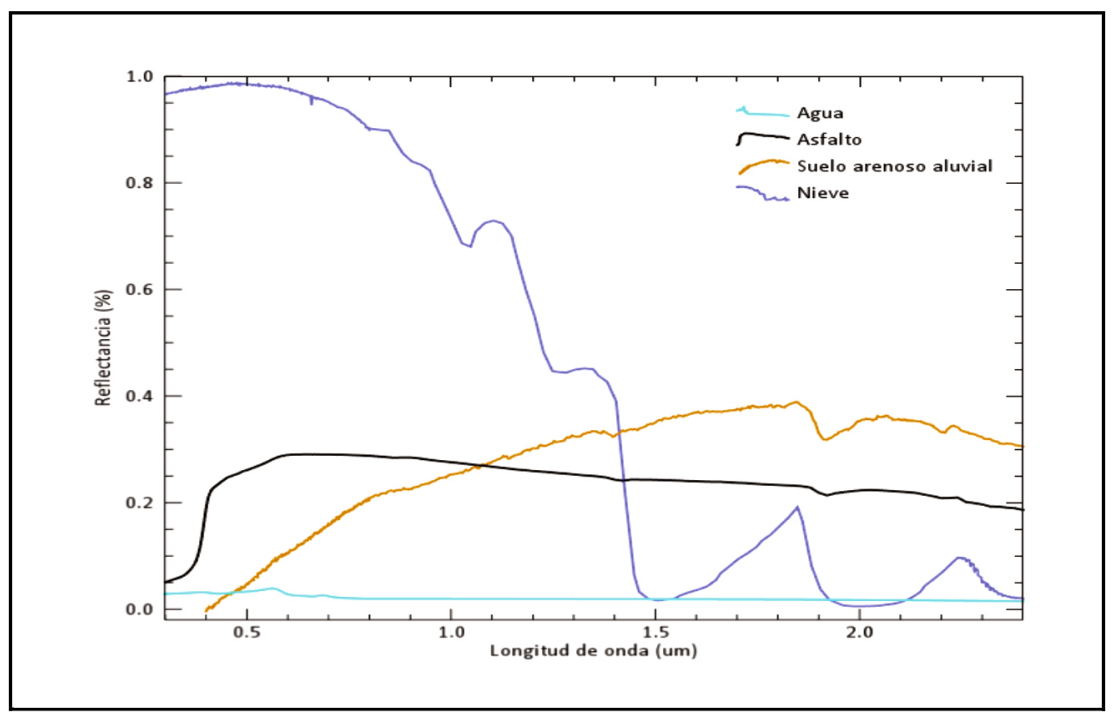

Fuente: Biblioteca espectral del USGS. Spectral Signatures for four common cover types in remote sensing. Source: USGS spectral library.

El agua por su parte solo refleja la gama de luz visible del espectro, con una muy escasa reflectancia en el infrarrojo, lo cual permite discriminar fácilmente ésta cubierta de otras superficies, como se observa en la Figura 2.

Con respecto a la vegetación, hay que considerar la propiedad reflectiva de las hojas, que varía en función de la forma de las mismas, su contenido en humedad y el estado fenológico. También hay que considerar las características morfológicas/morfométricas de la planta, como su altura, porte y grado de recubrimiento o densidad. Otro factor es la propia situación topográfica en el entorno de la planta o de la vegetación a estudiar (pendiente, orientación, etc.).

Al tomar en cuenta todos estos factores, el comportamiento típico de la vegetación vigorosa muestra una baja reflectividad en el espectro visible, con un máximo relativo en torno a los $0,55 \mu \mathrm{m}$, que es lo que permite percibir la vegetación de color verde. La vegetación sana en el infrarrojo cercano presenta una alta reflectividad, que desciende paulatinamente hacia el infrarrojo medio. (Mather, 2004). Este comportamiento 
Rubén Martínez-Barbáchano, Gustavo Adolfo Solis-Miranda. Caracterización Espectral y Detección de Flecha Seca en Palma Africana en Puntarenas, Costa Rica

de la vegetación se relaciona con los pigmentos presentes en las hojas, la estructura del mesófilo, y la cantidad de agua almacenada en las mismas. Todos los pigmentos absorben en la banda del espectro en torno a 0,45 $\mu \mathrm{m}$, mientras que uno de ellos presenta una segunda banda de absorción en torno a 0,64 $\mu \mathrm{m}$. (Chuvieco-Salinero, 2010). Entre ambas bandas existe un sector en el cual el efecto absorbente de los pigmentos es menor, y mayor la reflectividad. Dicha banda se corresponde con el verde, y la responsable de ello es la clorofila. Se trata de una característica común a cualquier cubierta vegetal, no obstante, existen diferencias (Mather, 2004). Por ejemplo, a partir de $0,7 \mu \mathrm{m}$ las coníferas (pinos y cipreses) tienden a presentar una reflectividad menor que las especies de hoja caduca (robles) como se muestra en la Figura 3.

Figura 3. Curvas de reflectividad de varios tipos de vegetación.

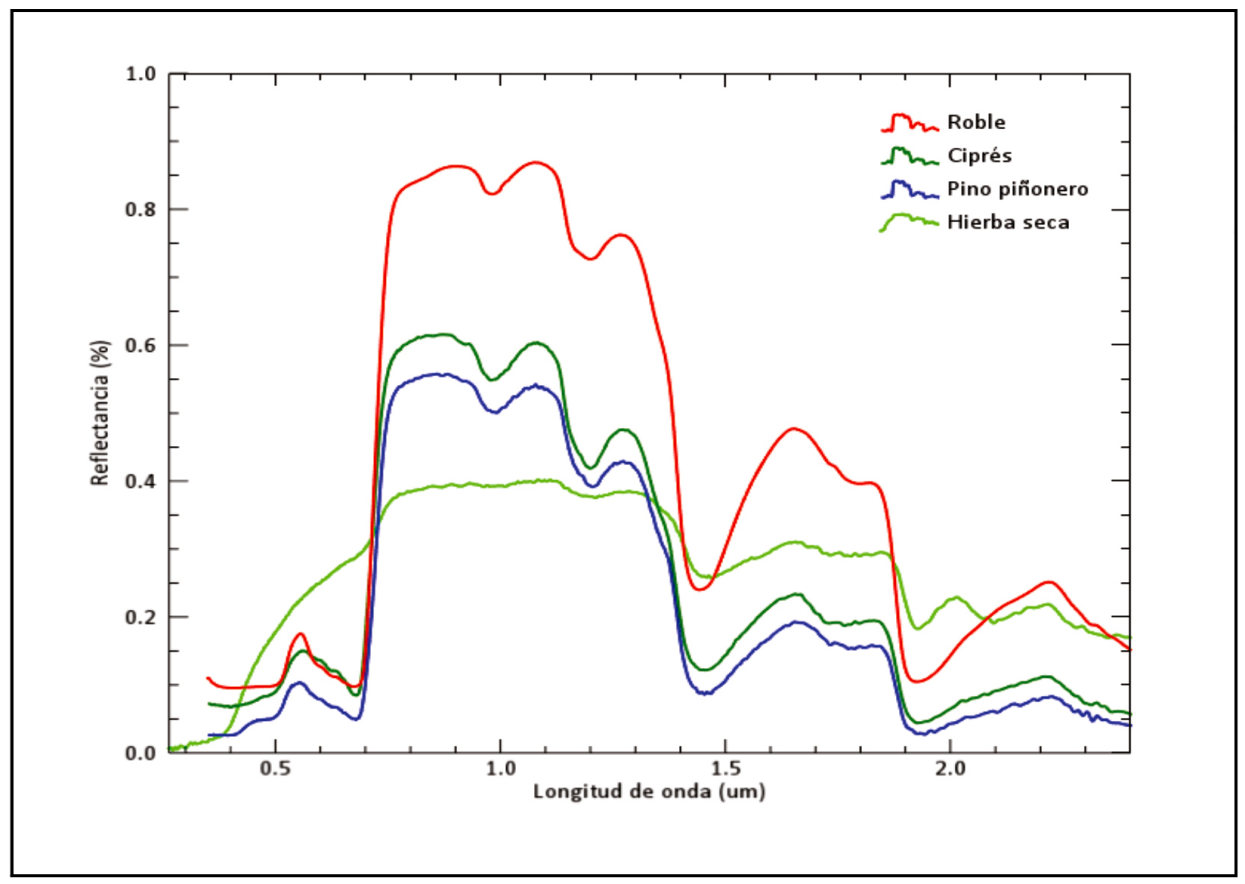

Fuente: Biblioteca espectral del USGS. Spectral reflectance curves of some vegetation types. Source: USGS spectral library. 
En lo relativo al incremento de la reflectividad en el infrarrojo cercano, parece que se debe a la estructura interna celular de la hoja, que ejerce una elevada influencia. Existe una capa esponjosa en el interior de la hoja, con cavidades que dispersan la mayor parte de la energía incidente en la banda del espectro electromagnético que coincide con el infrarrojo cercano. Por esta razón, en cualquier hoja sana se tendrá una alta o muy alta reflectividad en el infrarrojo cercano, pero muy baja reflectividad en el espectro visible. A partir de 1,4 $\mu \mathrm{m}$ se hace patente el efecto absorbente del agua, por lo que la reflectividad de la vegetación sana se reduce drásticamente en el infrarrojo medio (Chuvieco-Salinero, 2010).

De todo ello, se deduce que el contraste más nítido en la reflectividad espectral de la vegetación sana se produce entre las bandas visibles (muy especialmente el rojo) y el infrarrojo cercano. Se podría por ello enunciar como principio general que a mayor contraste entre dichas bandas (rojo e infrarrojo cercano) mayor será el vigor de la masa vegetal observada, y, por tanto, más fácil será discriminar ésta de otras cubiertas presentes en el mismo lugar (Figura 3). Este principio sirve para construir los Índices de Vegetación (Chuvieco-Salinero, 2010).

Cualquier estrés presente en la vegetación se manifestará en un comportamiento espectral diferente del descrito (descenso del contraste entre rojo e infrarrojo cercano). En el caso de que la hoja esté en estado de senescencia (a punto de caer) pierde clorofila, y por tanto ofrece mayor reflectividad entre las bandas del azul y el rojo (por eso se torna amarilla). Además, cuando la hoja es ya senescente, su estructura celular interna se deteriora, y por ello da una reflectividad más baja en el infrarrojo cercano.

Las deficiencias nutricionales y otras patologías en Palma africana (Elaeis guineensis) han sido estudiadas mediante espectrómetros, a nivel de copa o de hoja, demostrando su utilidad en la detección de infecciones por hongos del género Ganoderma sp. (Jayaselan et al., 2017).

La presente investigación pretende establecer una base metodológica de obtención de firmas espectrales en campo en el cultivo de palma africana (Elaeis guineensis), para identificar diferentes tipos de tratamiento y patologías como la flecha seca. Se trabaja para ello en las longitudes de onda propias de los estudios de vegetación mediante espectroscopía, dentro del rango que permite el dispositivo FieldSpec $®$ HandHeld 2 de la compañía ASD Inc., que varía, entre 325 y 1075 nanómetros (espectro visible e infrarrojo cercano). 
Rubén Martínez-Barbáchano, Gustavo Adolfo Solis-Miranda. Caracterización Espectral y Detección de Flecha Seca en Palma Africana en Puntarenas, Costa Rica

El objetivo de este trabajo fue caracterizar espectralmente la palma africana (Elaeis guineensis jacq.) por medio de espectro-radiometría de campo, en plantas sanas y afectadas por la flecha seca.

\section{Materiales y métodos}

Se caracterizó, mediante espectro-radiometría de campo, la respuesta espectral de plantas de tres años de palma africana en fincas experimentales bajo tres condiciones fitosanitarias; niveles de afectación por flecha seca 1 (nivel de afectación leve), 2 (nivel de afectación media) y 3 (nivel de afectación alta). Además, se comparó la respuesta espectral en estado fitosanitario óptimo (sano), o en condición de estrés hídrico. Con base en estos tratamientos, se determinará si existen diferencias en el comportamiento espectral de la planta de palma africana.

La magnitud o parámetro fundamental que sustenta el presente estudio es la reflectancia. Las mediciones de reflectancia se hacen generalmente usando la radiancia, irradiancia o una combinación de ambas. El presente estudio se desarrolló en condiciones de trabajo de campo, y, por tanto, utilizando la radiancia solar para medir reflectancia de una cubierta vegetal, en este caso las hojas de palma africana (Elaeis guineensis) en un cultivo experimental bajo condiciones de manejo controladas.

Se utilizó un reflector lambertiano en las mediciones de iluminación incidente, dependiente de la radiación solar. El uso de un reflector (generalmente llamado panel de referencia o espectralón) proporciona una correcta estimación de la irradiancia incidente en la superficie muestreada. Dado que la radiancia reflejada por el panel es muy próxima al total de energía incidente en la muestra, dicha lectura es usada en el denominador de la reflectancia, en lugar de la irradiancia. Es decir:

\section{Reflectancia $=$ energía reflejada por la superficie por reflexión energía incidente en la superficie}

El panel blanco de referencia fue ubicado cerca de los objetos a muestrear (foliolos) y orientado para recibir toda la iluminación incidente; al mismo tiempo, se evitó proyectar cualquier tipo de sombra sobre el panel, así como la posible luz reflejada de objetos circundantes. Utilizando el sol como fuente de iluminación, se colocó el panel blanco de referencia 
junto a las muestras medidas y se calibró con cada muestra para que las curvas de reflectancia obtenidas fueran coherentes con la intensidad lumínica del momento de medición.

El panel de referencia ve caer el mismo flujo energético (irradiancia) en su superficie, que el elemento muestreado, y refleja la mayor parte de dicha energía como radiancia. Como usuarios del espectro-radiómetro se puede recoger radiancia del panel directamente, así como radiancia del elemento o superficie muestreada (foliolos de hoja, en este caso). Ello permite el cálculo de reflectancia (de 0 a 1), eliminando el requerimiento de realizar calibraciones radiométricas, propio de las imágenes satelitales.

Para la obtención de firmas espectrales, se midieron 29 plantas de palma africana, de las cuales se obtuvieron aproximadamente veinte foliolos por muestra, cortados de las hojas del dosel (entre las hojas número 1 y 4) que son las más expuestas a la radiación solar, considerando los siguientes criterios:

- $\quad$ Por el tratamiento al que está sometida la plantación. Las mediciones se realizaron sobre cuatro tipos de ensayos diferentes, dentro del bloque de la plantación de palma africana; los bloques de tratamiento fueron los siguientes:

- Bloque "control", que se refiere al tratamiento del suelo, que en este caso no incluye ningún tipo de tratamiento edáfico.

- $\quad$ Bloque "control + rastra", se refiere a prácticas de arado superficial que contribuyen a una cierta oxigenación y descompactación del suelo.

- Bloque "fertilización + riego", que hace referencia a suelo con fertilización orgánica (deshechos vegetales de poda de la propia palma) y riego.

- Bloque "fertilización" incluye solo fertilización orgánica de suelo como la del caso anterior, pero sin riego.

- Por estado fitosanitario, dado por el criterio agronómico de un especialista del Centro de Investigaciones Agronómicas de la Universidad de Costa Rica, que efectúa una evaluación visual del grado de afectación por flecha seca. Los niveles de afectación leve, media o 
alta se pueden establecer de acuerdo a la presencia de síntomas iniciales (leve) como deshidratación y clorosis, epinastis (amplitud del ángulo de inserción foliar) que indicaría afectación media y, finalmente, necrosis profunda y generalizada, con síntomas como quemazón de los folíolos de las hojas jóvenes, clorosis y epinastis que indicaría afectación grave (Nieto-Páez, 1996).

Por todo ello, cada firma espectral obtenida es representativa de la particular condición de cada planta, desde el punto de vista fitosanitario, de tratamiento, desarrollo y otros factores (ambientales y edáficos).

Para validar la metodología adoptada se utilizó la herramienta de "leaf clip" o sonda vegetal, con el objetivo de cuantificar y valorar cómo afecta el corte del foliolo a la respuesta reflectiva del mismo. Se obtuvieron dieciséis firmas espectrales de un foliolo de plántula de palma africana durante quince minutos con mediciones cada minuto.

Los datos de reflectancia que se obtuvieron con el sensor óptico terrestre se descargaron e integraron en forma de firmas con el software específico de la compañía ASD ViewSpecPro, que permite graficar los muestreos.

La gran ventaja de este tipo de dispositivos es la sencillez respecto de los factores a tener en cuenta previamente a su uso, comparado con el de las imágenes de satélite. No se requiere, por ejemplo, de complejas correcciones atmosféricas basadas en modelos de transferencia radiativa, ya que se mide directamente en el terreno.

\section{Área geográfica de estudio}

Con respecto al contexto geográfico, el mejor desempeño del cultivo en Costa Rica se ha observado en zonas con un clima tropical húmedo, con una precipitación anual entre 2500 y $3500 \mathrm{~mm}$ bien distribuidos, sin una estación seca bien definida (precipitación mínima por mes de $125 \mathrm{~mm}$ ). La temperatura media necesaria está en los ámbitos entre 25 y $27^{\circ} \mathrm{C}$, con una máxima promedio de $29-33{ }^{\circ} \mathrm{C}$, y una mínima promedio de $22-24{ }^{\circ} \mathrm{C}$.

El clima del Pacífico Central presenta cuatro meses de estación seca, cuya precipitación es inferior a los requerimientos de la palma (menos de $199 \mathrm{~mm} / \mathrm{mes}$ ) y cuatro meses en los que la precipitación es excesiva (más de $400 \mathrm{~mm} / \mathrm{mes}$, durante los meses de julio a octubre). Por lo tanto, en esta región para la producción comercial de palma se requiere contar con 
un buen sistema de avenamiento, para mantener la tabla de agua entre 1,5 $\mathrm{m}$ a $3 \mathrm{~m}$ bajo la superficie del suelo y hacer riegos suplementarios en los meses más secos.

El trabajo se realizó en la finca experimental de la cooperativa Coopecalifornia, a nombre de Cooperativa de Producción de palma africana California R. L., ubicada en la provincia de Puntarenas (6), cantón de Parrita (9), distrito Parrita (1), cuya área correspondiente es de seis hectáreas. Se aporta a su vez, la imagen de la distribución de las plantas de palma africana dentro de la finca en estudio, como se muestra en la Figura 4.

Figura 4. Ubicación de las 29 Palmas Africanas seleccionadas y medidas en campo en Parrita, Puntarenas, Costa Rica.

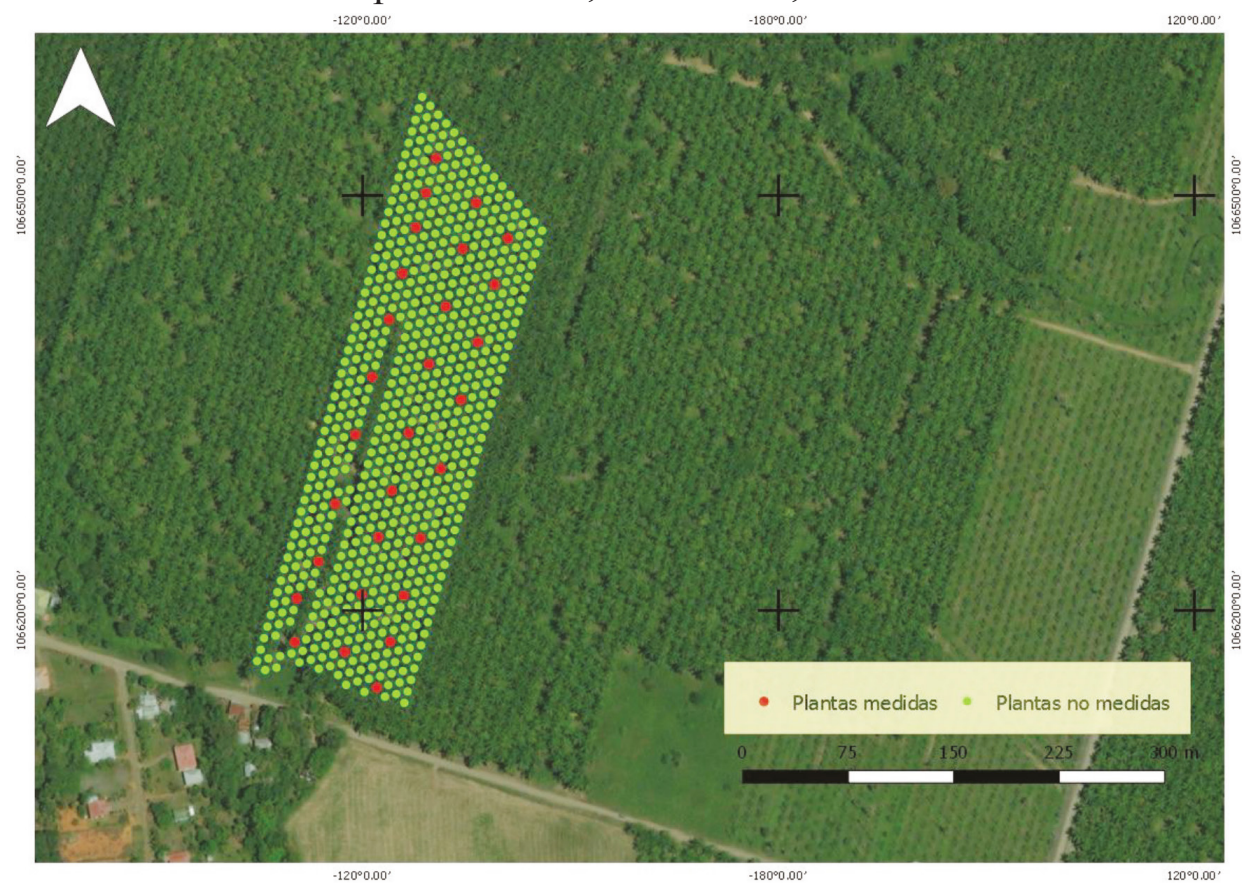

Fuente: Centro de Investigaciones Agronómicas, UCR.

Mediciones en campo.

Las mediciones de campo se efectuaron durante los meses de febrero, marzo, abril y mayo de 2016. Las muestras se toman entre las 8:00 y 12:00 a.m., en condiciones de cielo despejado y un rango de temperaturas 
Rubén Martínez-Barbáchano, Gustavo Adolfo Solis-Miranda. Caracterización Espectral y Detección de Flecha Seca en Palma Africana en Puntarenas, Costa Rica

entre los $30-35^{\circ} \mathrm{C}$ durante las tres mediciones. Todos los individuos de la plantación objeto de estudio poseen una numeración por bloque de tratamiento, y además están georreferenciadas con coordenadas UTM en la proyección oficial de Costa Rica, CRTM05.

Dada la altura de las plantas de palma, superior a los dos metros en la mayoría de los casos, no se pudieron utilizar las técnicas no invasivas propias de la teledetección, que hubieran requerido de una grúa u otro soporte móvil para medir el dosel a cierta altura. Por ello, la obtención de firmas espectrales en hoja se realizó mediante la corta selectiva de los foliolos de las hojas en campo y su posterior colocación en horizontal sobre el suelo, bajo condiciones homogéneas de medición (entre 15 y $20 \mathrm{~cm}$ de distancia de los foliolos) con el espectro-radiómetro ASD HandHeld 2 (Figura 5).

Figura 5. Obtención de la firma espectral de Palma africana (Elaeis guineensis) a una distancia aproximada de $15 \mathrm{~cm}$, en Parrita, Puntarenas, Costa Rica.

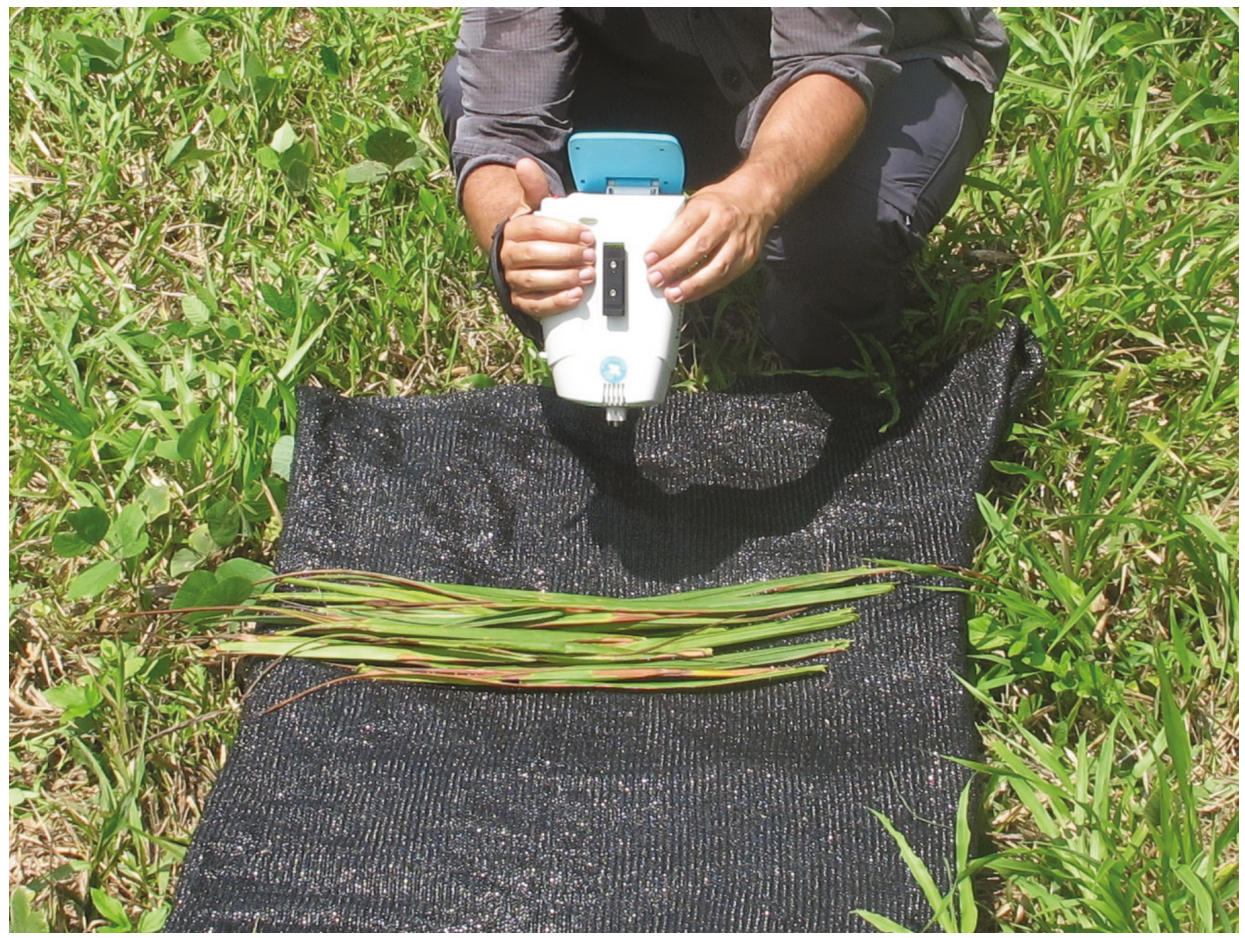


Se midieron los foliolos cortados en el haz, y se utilizó un plástico de color negro colocado por debajo de las muestras con dimensiones de $1 \times 1 \mathrm{~m}$, para evitar la contribución de la radiación de cualquier otro tipo de cubierta (suelo), como se muestra en la Figura 5 y $6 \mathrm{~A}$. Igualmente, se trabajó con vestimenta de color oscuro para evitar dicha contribución a la reflectancia, que posteriormente, sería difícilmente separable de la señal propia de la cubierta. Con todo ello, se aseguró que la superficie que quedó por debajo de los foliolos era absortiva en todas las longitudes de onda cubiertas por el espectro-radiómetro. Se seleccionaron sistemáticamente veinticinco foliolos de la parte intermedia de la tercera hoja bien formada del ápice hacia la parte baja de cada rama, debido a las características nutricionales de dicha hoja y a su posición perpendicular a la radiación solar. Por otra parte, la medición de la respuesta espectral de los foliolos se realizó inmediatamente después del corte, para evitar la pérdida de humedad del foliolo que provocaría marchitez, y por tanto una disminución de la reflectividad en el infrarrojo cercano (Figura 5). 
Rubén Martínez-Barbáchano, Gustavo Adolfo Solis-Miranda. Caracterización Espectral y Detección de Flecha Seca en Palma Africana en Puntarenas, Costa Rica

Figura 6. A. Corte y colocación de los foliolos de palma en el zarán en Parrita, Puntarenas, Costa Rica.

B. Calibración y optimización de dispositivo en Parrita, Costa Rica.

C. Relación entre superficie y ángulo de observación según el fabricante. Fuente: Manual de usuario del FieldSpec HandHeld 2 de ASD.

D. Obtención de firma espectral con el dispositivo en Parrita, Costa Rica.

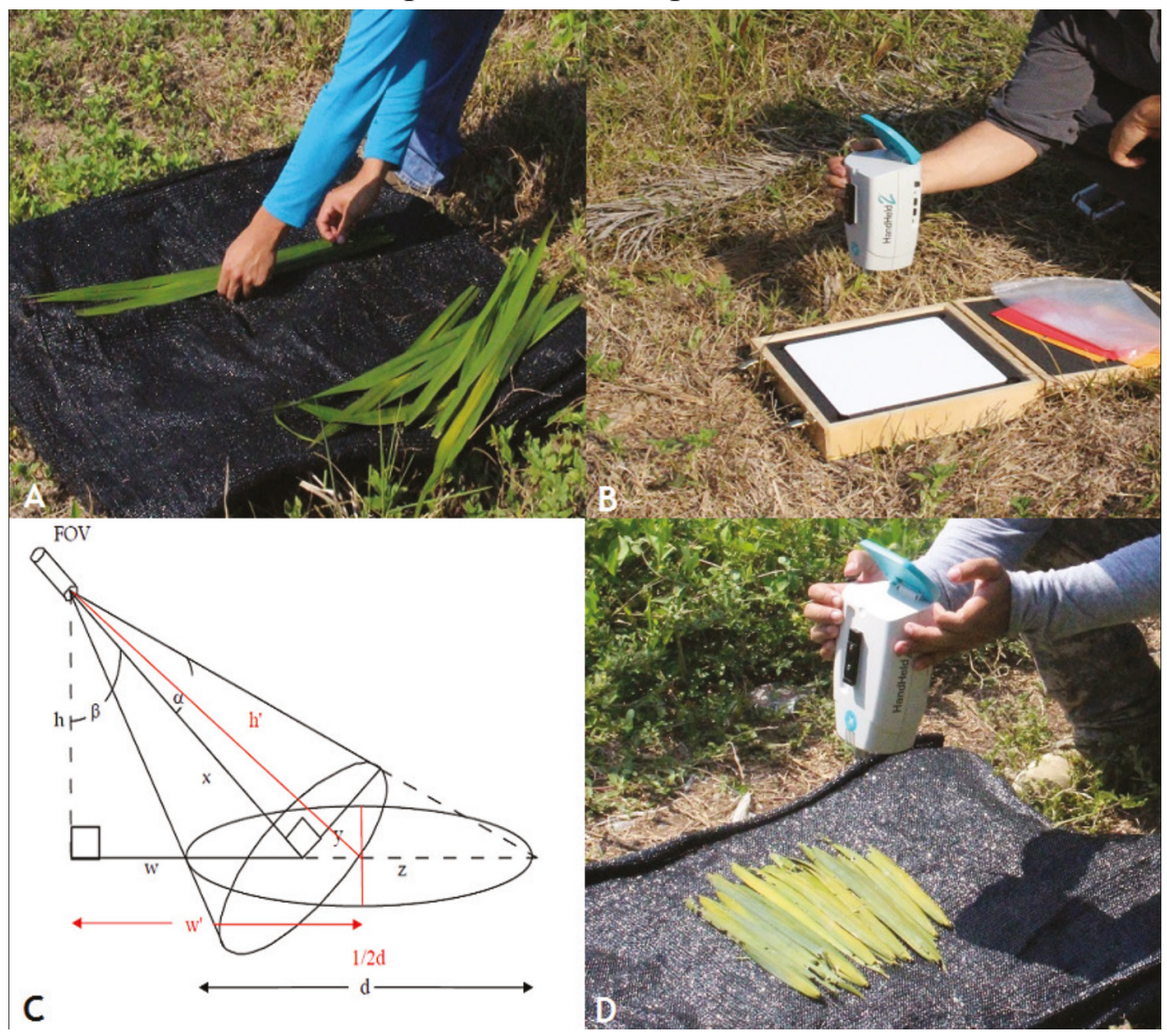

Antes de cada medición se requirió de un proceso de optimización lumínica y calibración a blanco de máxima reflectancia con el espectroradiómetro (proceso descrito anteriormente) como paso previo a la obtención de la respectiva curva de reflectancia (Figura 6B). 
Se realizó una comparación del comportamiento de la curva de reflectancia de los foliolos cortados con respecto a mediciones en hoja sin cortar y en hoja muerta.

Con respecto a la geometría de observación del sensor, se trata de un parámetro dependiente de las indicaciones del fabricante. Según éste, la distancia entre el sensor y la planta se establece en función del FOV (Field of View, o campo de visión), dependiendo de la superficie foliar que determinó la distancia de medición (Figura 6C). Como criterio general se asumió que las mediciones tendrían un ángulo próximo a los 0 grados, en cuyo caso el campo de visión debe ser el doble de la distancia al objeto medido, que en este caso es la superficie abarcada por los foliolos. Es decir, aproximadamente 15-20 cm de distancia al objeto (Figura 6D).

No se acometió un muestreo aleatorio, sino que se siguió un criterio por grados de afectación por flecha seca en planta y por el tipo de tratamiento al que fueron sometidas. En marzo de 2016, se obtuvieron catorce firmas espectrales de los tratamientos "fertilización + riego", "control" y "control+rastra". En abril del 2016, se obtuvieron siete firmas espectrales de los tratamientos "fertilización", "fertilización+riego" y "control". Finalmente, en mayo de 2016, ocho firmas espectrales de los tratamientos "fertilización", "control+rastra" y "fertilización+riego" con la distribución espacial mostrada en la Figura 4.

\section{Limitaciones}

Las limitaciones del proyecto son de tipo técnico, logístico y ambiental:

- $\quad$ Las firmas espectrales obtenidas tienen el ruido propio de las mediciones en campo, como los picos de absorción del agua, que se incrementan por la elevada humedad atmosférica propia de la zona intertropical.

- La electrónica del sensor (sensibilidad, tiempo de integración, etc.) provoca que el trabajo quede condicionado por la muy escasa durabilidad de las baterías (cuatro pilas alcalinas AA).

- Las limitaciones ambientales se refieren a las condiciones atmosféricas en el momento de los muestreos de campo; cobertura nubosa, lluvias, estado fenológico de la vegetación, hora del día (ángulo solar) y condiciones locales son factores condicionantes de la firma espectral resultante. 
Rubén Martínez-Barbáchano, Gustavo Adolfo Solis-Miranda. Caracterización Espectral y Detección de Flecha Seca en Palma Africana en Puntarenas, Costa Rica

\section{Recursos técnicos}

Al ser utilizado como un sensor pasivo, el sensor óptico terrestre utiliza la radiación solar reflectada por la cubierta (foliolos de hoja de palma) en el espectro visible e infrarrojo cercano. Por lo tanto, influyen las condiciones atmosféricas y de iluminación del momento de la obtención de la firma espectral. El fabricante no aconseja su uso en condiciones de alta cobertura nubosa.

El SOT que se va a utilizar para el presente estudio va a ser un radiómetro de campo de la compañía ASD (ver figura 7) con manejo integrado y las siguientes características técnicas:

- $\quad$ Rango $325 \mathrm{~nm}-1075 \mathrm{~nm}$.

- Velocidad de integración variable.

- Ordenador y teclado integrados. Pantalla VGA color.

- $\quad$ Peso 1,3 kg.

- Memoria interna más de 20000 espectros.

- $\quad$ Conectividad: 2 puerto USB; 1 puerto mini USB.

- $\quad$ Software propio ara post proceso (RS3 y ViewSpec).

- Accesorios y calibraciones.

Figura 7. Radiómetro de campo "FieldSpec HandHeld 2" de ASD.

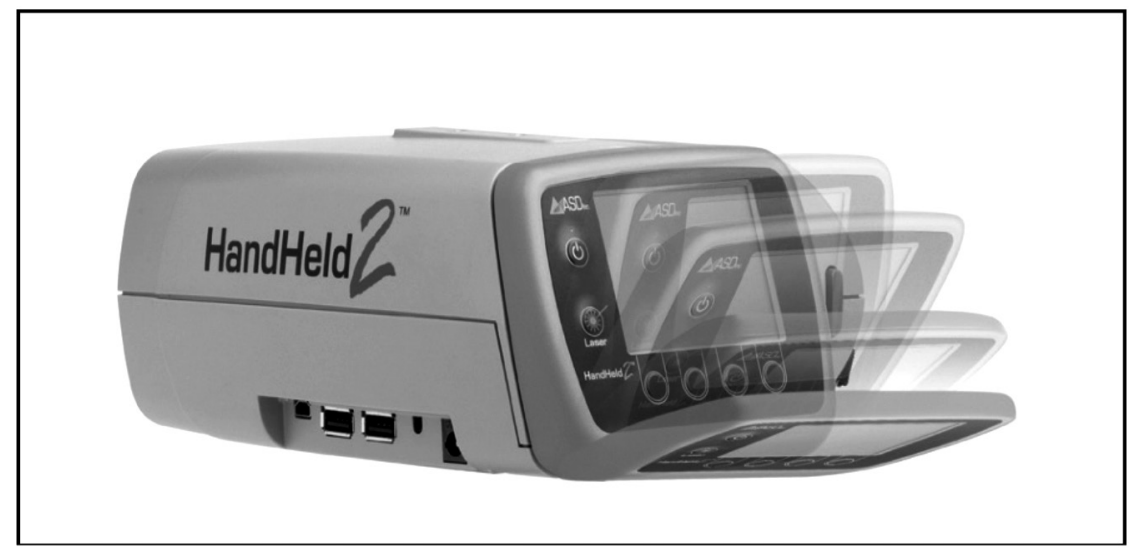

Fuente: Manual de Usuario - FieldSpec ${ }^{\circledR}$ HandHeld 2.

Se dispuso de un panel blanco de referencia o espectralón, una pieza fundamental en espectroscopía de campo, ya que permite calibrar el 
espectro-radiómetro a las condiciones lumínicas del momento de medición. El espectralón es una pieza elaborada en material blanco de politetrafluoroetileno, reflectante en un 99\%, tiene un certificado de calibración vigente.

También se obtuvieron firmas espectrales con el empleo de este dispositivo como un sensor activo, mediante el accesorio "Leaf Clip" o sonda de planta que tiene su propia fuente de energía (lámpara halógena de baja intensidad; $6,5 \mathrm{~W}$ ) y recoge la respuesta espectral de una hoja a través de un cable de fibra óptica, como se muestra en la figura 8.

Figura 8. Leaf Clip o sonda de planta del FieldSpec HandHeld 2" de ASD.

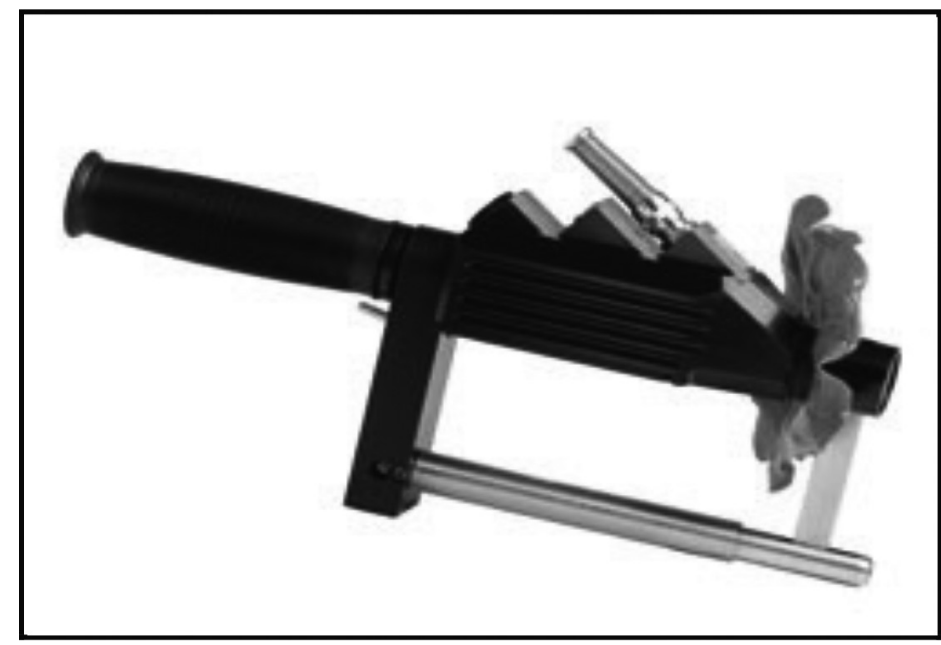

Fuente: Manual de Usuario - FieldSpec® HandHeld 2.

La utilización de un sensor óptico terrestre ha demostrado su versatilidad en la detección del estrés hídrico y su relación con la calidad del fruto en determinadas especies cultivadas, como el olivo (olea europaea) o el melocotonero (prunus persica), "a través de la medición de la reflectancia a nivel de hoja y su relación con el estrés a nivel de copa" (Suárez et al., 2009).

\section{Resultados}

\section{Datos obtenidos en campo}

Previamente a las mediciones en campo, se obtuvieron firmas espectrales de un mismo foliolo cada tres minutos, aproximadamente, en 
Rubén Martínez-Barbáchano, Gustavo Adolfo Solis-Miranda. Caracterización Espectral y Detección de Flecha Seca en Palma Africana en Puntarenas, Costa Rica

un lapso de dieciséis minutos desde el instante del corte hasta la última medición, con objeto de registrar el efecto fisiológico que el corte tiene en la evolución de la reflectancia del foliolo.

La Figura 9 muestra el efecto que el corte del foliolo produce desde el punto de vista fisiológico y de la respuesta en la curva de reflectancia. Como era previsible, tomando en cuenta la pérdida de humedad como consecuencia del corte, la reflectividad desciende entre 700 y 850 nanómetros, pero lo hace tan sólo un $0,05 \%$ durante el lapso de 16 minutos desde el momento del corte (efectuado a las 12:08) hasta la última medición (efectuada a las 12:24). La imagen citada ilustra lo expuesto, con un descenso lento pero constante en la reflectividad, con el paso del tiempo, desde el instante del corte y separación del foliolo. Resulta evidente, en este sentido, que la deshidratación de la hoja (a partir de 700 nanómetros) es más rápida que la pérdida de clorofila en el espectro visible (entre 500 y 600 nanómetros). Por otra parte, se observó un incremento de la reflectancia entre 700 y 790 nanómetros (infrarrojo más cercano) en las firmas obtenidas durante los primeros cuatro minutos desde el instante del corte del foliolo.

Figura 9. Evolución temporal de la reflectancia obtenida con sonda vegetal tras el corte de un foliolo de palma africana (Elaeis guineensis).

Puntarenas (Costa Rica) abril de 2016.

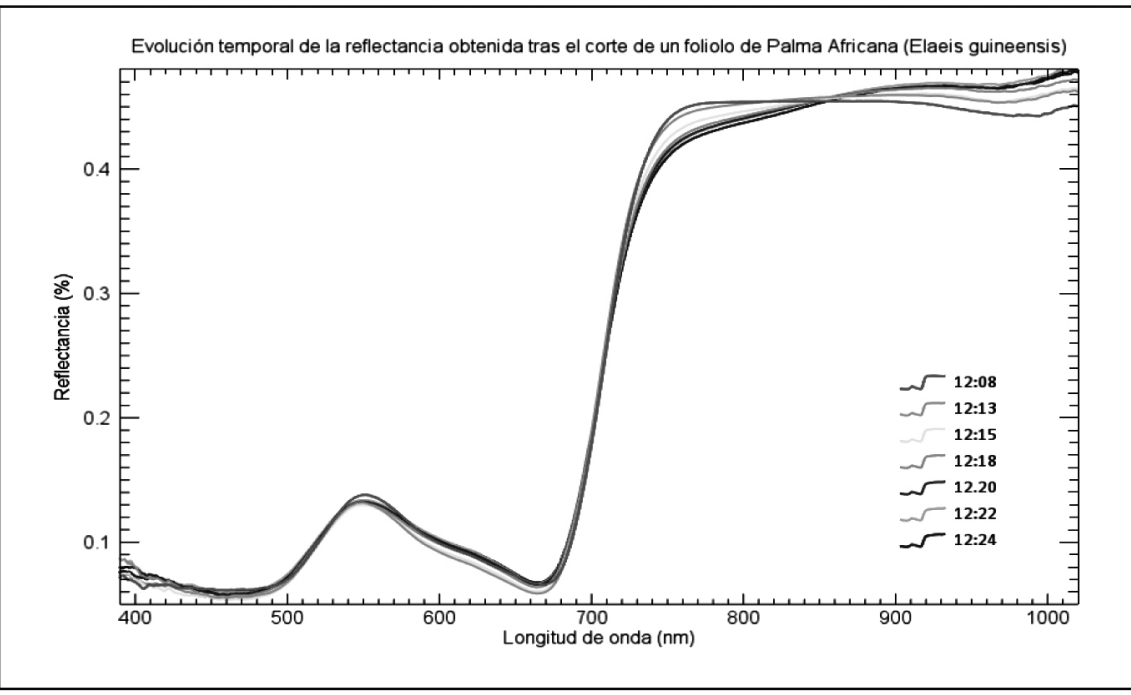


A partir de los 850 nanómetros de longitud de onda, se produce una reacción fisiológica no esperada en los foliolos recién cortados, ya que en los instantes inmediatos al corte, la reflectividad en lugar de descender (cosa que hace a partir de los cuatro minutos) se incrementa muy levemente (Figura 10). Esta mayor reflectividad proporcional al paso del tiempo en los primeros tres o cuatro minutos, probablemente corresponde al calentamiento de la hoja como consecuencia del cierre estomático, lo cual impide la pérdida de energía en forma de calor latente. Ello podría ser una respuesta defensiva de la planta, ya que se comprobó la misma respuesta en otras especies. Dicho experimento sirvió para validar la metodología de corte de foliolos en hoja de palma, ya que la esperable deshidratación y su consiguiente reflejo en la firma espectral no se producen hasta pasados cinco minutos después del corte, a pesar de las elevadas temperaturas (entre 30 y $37^{\circ} \mathrm{C}$ ).

Figura 10. Incremento reflectivo obtenido con sonda vegetal en los primeros cuatro minutos tras el corte de un foliolo de palma africana (Elaeis guineensis). Puntarenas (Costa Rica) abril de 2016.

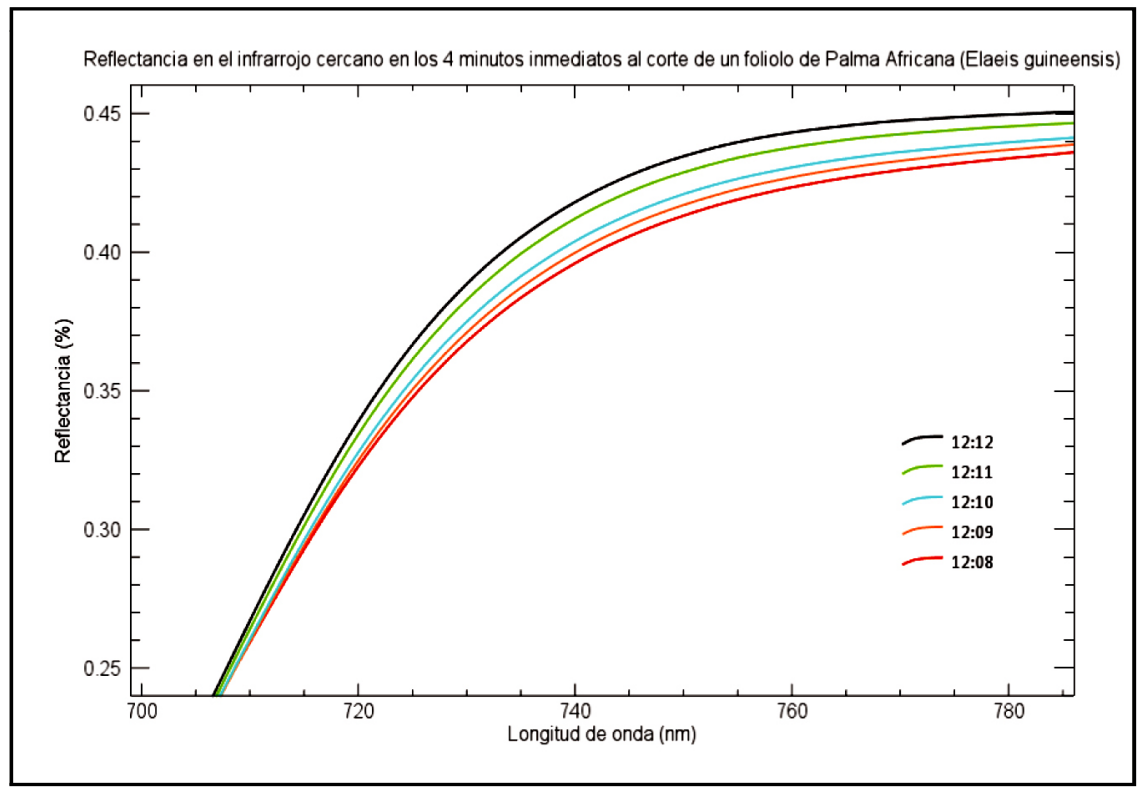


Rubén Martínez-Barbáchano, Gustavo Adolfo Solis-Miranda. Caracterización Espectral y Detección de Flecha Seca en Palma Africana en Puntarenas, Costa Rica

En la Figura 11 se muestran las cuatro firmas espectrales promediadas de los cuatro tipos de tratamiento de la plantación en estado fitosanitario sano.

Figura 11. Comparación de las firmas espectrales correspondientes a los cuatro tipos de tratamientos de Palma africana (Elaeis guineensis).

Parrita, Costa Rica (April 2016).

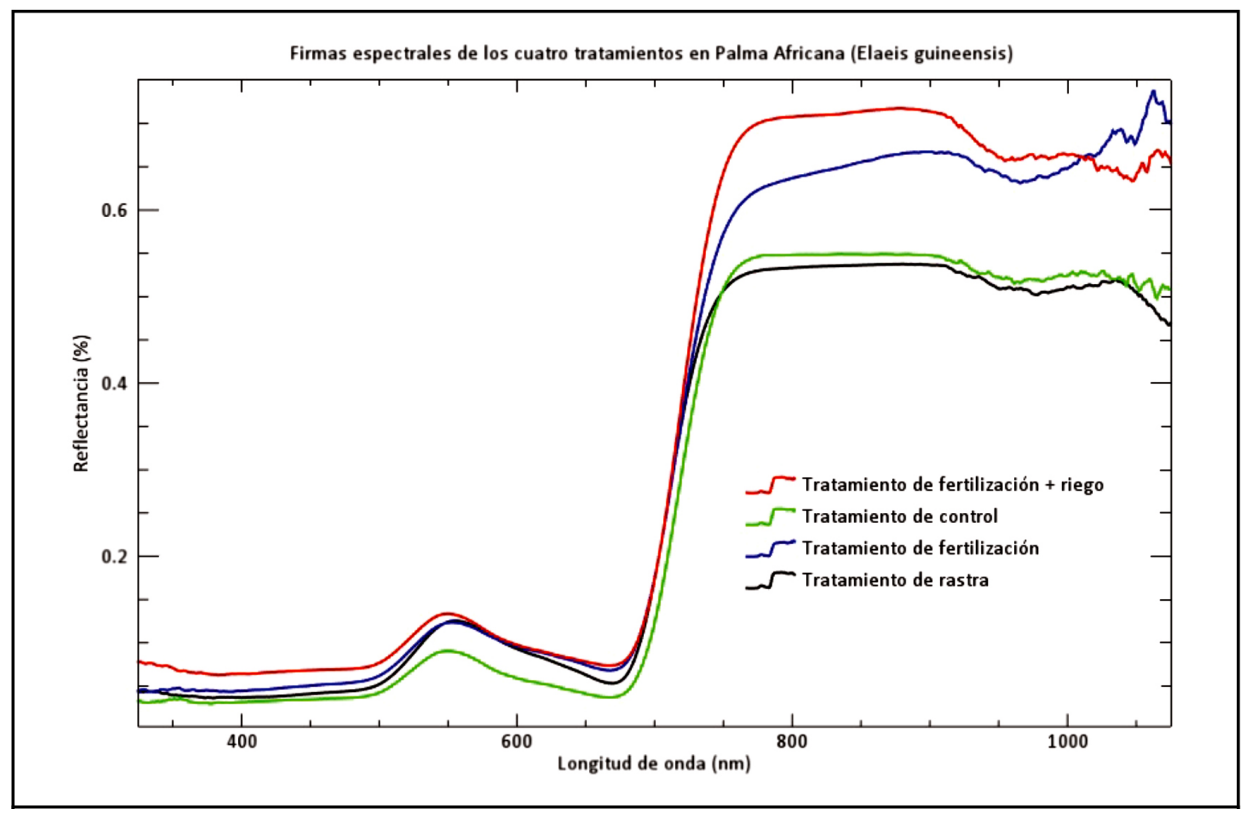

En un primer paso se elaboraron los gráficos de todas las firmas espectrales capturadas en campo, y posteriormente se generaron las curvas suavizadas y la respectiva curva media correspondiente a cada tipo de tratamiento, mediante la utilización de bases B-splines (Ramsay y Silverman, 2005).

El método de suavizado se basa en la siguiente función:

$$
\begin{aligned}
& G \\
& \mathrm{x}(t)=\Sigma \\
& g=1
\end{aligned} C_{\mathrm{g}} \Phi_{\mathrm{g}}(t)=\Phi(t)^{T} C
$$


Siendo $\Phi(t)=\left(\Phi_{l}(t), \ldots ., \Phi_{G}(t)\right)^{T}$ un vector de funciones de base, $C=\left(C_{1}, \ldots, C_{\mathrm{G}}\right)^{T}$ un vector de coeficientes de base y $G$ el número de funciones de base. Los coeficientes de base fueron calculados a partir del sumatorio de mínimos cuadrados de reflectancia:

$$
\sum_{i=1}^{G}\left(y_{\mathrm{i}}-\mathrm{x}\left(t_{i}\right)\right)^{2}
$$

Existió una marcada diferencia espectral entre los diferentes tipos de tratamiento en planta. Se aprecia claramente que el tratamiento con una mejor respuesta espectral, el de "fertilización + riego" fue seguido del tratamiento "fertilización" (Figura 11). La respuesta reflectiva de las plantas bajo tratamiento de "control" y "rastra" es claramente inferior, lo cual puede relacionarse tanto con el tipo de tratamiento como con el hecho de estar afectadas por flecha seca. Se puede inferir entonces que la afectación por flecha seca genera un descenso en los valores de reflectividad, a pesar del tratamiento al que esté sometido la planta.

Se compararon también tres firmas espectrales representativas de la reflectancia medida en foliolos cortados, en hoja de planta viva y en hoja marchita, con el siguiente resultado. 
Rubén Martínez-Barbáchano, Gustavo Adolfo Solis-Miranda. Caracterización Espectral y Detección de Flecha Seca en Palma Africana en Puntarenas, Costa Rica

Figura 12. Comparación de las firmas espectrales correspondientes a las plantas 53 (hoja de palma y foliolos de palma cortados) y una hoja muerta de la planta 59. Comparison of the spectral signatures corresponding to the plant 53 (cut palm leafs and cut palm leaflets) and a dead leaf of the plant 59. Parrita, Costa Rica (April 2016).

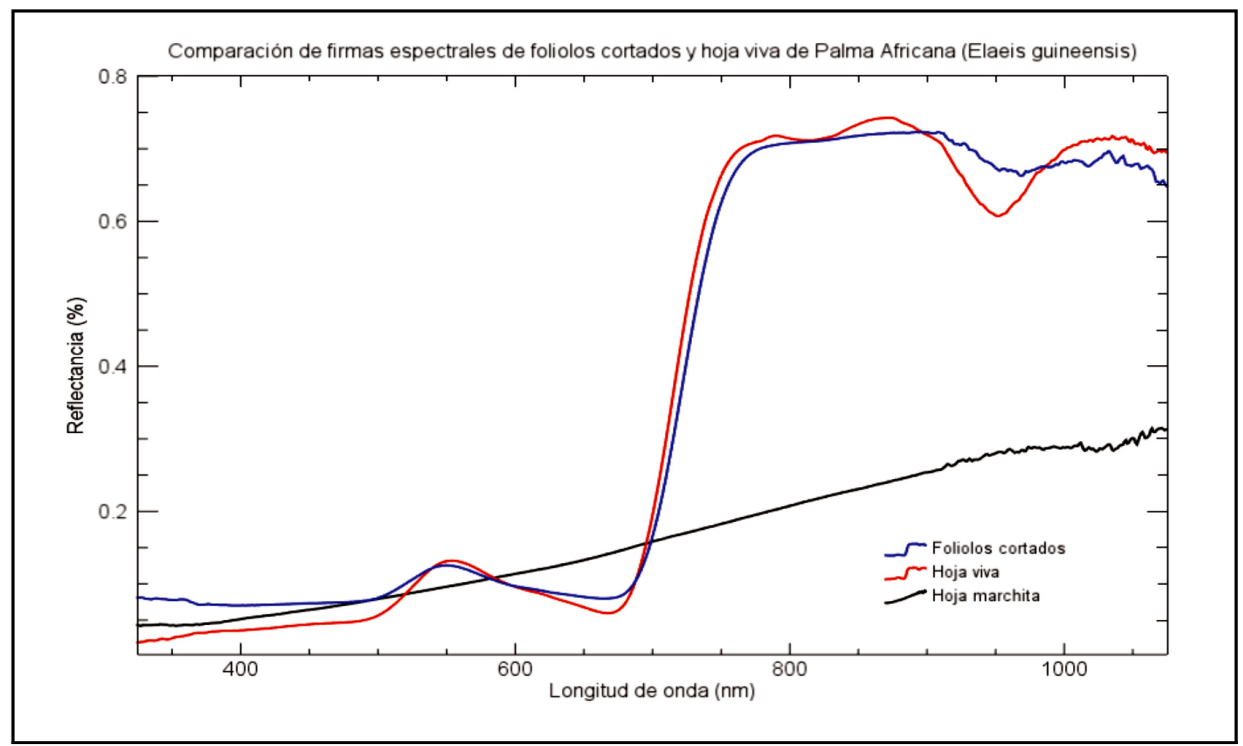

\section{Discusión}

De la Figura 12, puede deducirse que el espectro del infrarrojo cercano sirve no sólo para estimar la humedad o contenido en clorofila de unos foliolos cortados, sino que midiendo directamente en hoja viva, a una distancia igual a la anterior $(15-20 \mathrm{~cm})$, la curva de reflectancia refleja la estructura de una hoja de palma, con picos de absorción atmosférica en 820 y 910 nanómetros, relacionados con la estructura típica de una hoja de esta especie, y que difiere claramente del carácter continuo que presenta la curva de reflectancia de los foliolos cortados y agrupados sobre el zarán negro. Por último, el patrón de la curva de reflectancia que presenta la hoja marchita responde al esperado, siendo mucho menos reflectiva y más parecida a la del suelo desnudo.

Las firmas espectrales de campo adquiridas mediante radiómetros se utilizan para calibrar los valores de reflectividad estimados a partir de las imágenes (Escribano-Velasco, 2010). Por ello, las firmas espectrales 
obtenidas en hoja resultaron más adecuadas para establecer comparación o clasificación de imágenes satelitales, al incluir aspectos como los picos de absorción del agua o el efecto del albedo en la propia firma, que se manifiestan igualmente en las firmas de imágenes hiperespectrales de sensores como Hymap o Hiperion. Por el contrario, las firmas espectrales obtenidas a partir de foliolos cortados sirven para caracterizar espectralmente una hoja, y son más parecidas a las mediciones que pudieran obtenerse en laboratorio, con condiciones lumínicas estandarizadas y ambiente controlado.

Se puede inferir que las cuatro condiciones fitosanitarias (tratamientos) de la plantación estudiada tienen reflejo en un patrón de respuesta reflectiva identificable (Figura 11), aunque el tratamiento de "fertilización + riego" por sí mismo no se asocia necesariamente con una respuesta de mayor reflectividad debido a que bajo este tratamiento existen plantas enfermas. Dicho de otro modo, las plantas bajo tratamiento de "fertilización + riego" severamente afectadas por flecha seca, tienden a presentar menor reflectancia en el infrarrojo que otras plantas sin tratamiento ("control" y "control + rastra") que presenten una condición fitosanitaria sana (sin afectación por flecha seca).

Para futuros estudios de caracterización espectral y detección de enfermedades o estrés hídrico en plantas de palma africana, se sugiere disponer de un historial de firmas espectrales desde su estado de plántula hasta la edad máxima. Ello permite realizar un seguimiento histórico de cada planta en sus diferentes edades, y adaptar posibles tratamientos, tomando en consideración la tendencia o patrón cronológico de su respuesta reflectiva.

Si las firmas espectrales obtenidas van a servir para clasificación de imágenes satelitales y comparación con reflectancia a nivel de píxel, se recomienda obtener las firmas espectrales de la planta completa. En cambio, si lo que se busca es una caracterización reflectiva a nivel de hoja, en condiciones de campo, se recomienda obtener la firma espectral de los foliolos. Para mediciones en hoja en condiciones de laboratorio, existe el dispositivo denominado "Leaf Clip" (o sonda de fibra óptica) que aísla la respuesta espectral de la hoja de cualquier efecto atmosférico en la firma. En laboratorio, se controlan las condiciones y geometría de la iluminación para obtener datos independientes estandarizados. Sin embargo, al efectuar mediciones de campo se pueden recopilar datos representativos de la variedad de condiciones ambientales reales en que se encuentran los 
Rubén Martínez-Barbáchano, Gustavo Adolfo Solis-Miranda. Caracterización Espectral y Detección de Flecha Seca en Palma Africana en Puntarenas, Costa Rica

materiales estudiados, las cuales son difíciles de simular en laboratorio (Hernández, 2007).

Es importante estandarizar la obtención de las firmas espectrales con un ángulo de medición próximo a $0^{\circ}$ (que asegure un $\mathrm{FOV}$ de $25^{\circ}$ ) a una distancia de entre 15 y $25 \mathrm{~cm}$ del objeto medido (dependiendo del área del mismo) para reducir la variabilidad que los cambios angulares introducen en la respuesta espectral. Es importante tomar en consideración que al realizar mediciones verticales la proyección de la sombra del sensor y la persona que obtiene la firma deben quedar excluidas tanto del panel blanco de calibración como del objeto muestreado, lo cual se dificulta hacia las horas centrales del día.

\section{Conclusiones}

Se concluye entonces que existe un patrón espectral bien definido, relacionado con los diferentes tipos de tratamiento, por un lado, y con el grado de afectación por flecha seca. En general, las plantas en condición fitosanitaria sana, que además tuvieron un tratamiento de "fertilización + riego", presentaron las curvas de reflectividad más elevadas, en torno a un $0,7 \%$.

La influencia por flecha seca en la curva de reflectancia de las plantas tuvo un mayor peso, en la mayoría de los casos, que el tipo de tratamiento al que están sometidas. Se verifica así la posibilidad de detectar la patología de flecha seca mediante espectroscopía de reflectancia en condiciones de trabajo de campo. Esto es, especialmente constatable cuando se dispone de un historial de afectación por flecha seca prolongado en el tiempo.

Las observaciones expuestas en las mediciones realizadas en condiciones de laboratorio con "Leaf Clip" o sonda de fibra óptica (Figuras 9 y 10) sirven de base para validar una metodología basada en el corte selectivo y medición de foliolos en condiciones de campo (luz natural), ya que la reflectividad no varió sustancialmente transcurridos los primeros instantes al corte.

Para caracterizar espectralmente un cultivo en condiciones de campo, se requiere de la implementación de una serie de estándares metodológicos en las mediciones, que deberían de tener las siguientes características:

- $\quad$ Desde un punto de vista geométrico en las técnicas de muestreo, idealmente se requieren mediciones nadirales y azimutales cada 10 grados, que recojan toda la variabilidad de ángulos de incidencia solar posibles. 
- $\quad$ Desde el punto de vista temporal en los muestreos, para recoger toda la variabilidad espectral dichas mediciones deben de realizarse durante todo el día, al menos entre las 10:00 y las 15:00 (según especificaciones del fabricante).

- Se debe también disponer de muestreos representativos del tratamiento, edad y estado fenológico de las plantas, recogiendo toda su variabilidad.

- $\quad$ La flecha seca es una patología que actualmente se encuentra en estudio. Hay un desconocimiento generalizado acerca de su origen, vector de contagio y sintomatología en especies. Se desconoce si tiene un origen genético, bacteriano o vírico, pero su presencia deja una evidente "huella" espectral en las firmas.

\section{Referencias}

Bloembergen, Siegbahn, K. M. (2007). Uso de la Espectroscopía. Quimiláser. España: Universidad Complutense de Madrid.

Botero, J. (2009). Determinación del nivel foliar de nutrientes mediante espectroscopía de reflectancia. (Tesis MSc., Universidad Nacional de Colombia), Colombia.

Escribano-Velasco, P. (2010). Integración de técnicas espectrales para la detección y cuantificación de los tipos de cubiertas en ecosistemas áridos. Bases para un programa de seguimiento del P.N. Cabo de Gata-Nijar. (Tesis Dr., Universidad de Almería), ESP.

Ministerio de Agricultura y Ganadería de Costa Rica (MAG). (2007). Cadena agroalimentaria del cultivo de palma aceitera en el distrito Chires de Puriscal. MAG, CRC. Recuperado de http://www.mag. go.cr/bibliotecavirtual/a00061.pdf (consultado ene. 2016).

Nieto-Paez, L. E. (1996). Síntomas e identificación del agente causal del complejo Pudrición de Cogollo de la palma de aceite, Elaeis guíneensis Jacq. Revista Palmas, 17(2), 57-60.

Campbell, J.B. (2002). Introduction to remote sensing. $3^{\text {th }}$ ed. The Guilford Press, USA.

Chuvieco-Salinero, E. (2010). Teledetección ambiental: La observación de la Tierra desde el espacio. España: Editorial Ariel.

Goetz, A.F., Vane, G., Solomon, J. E. \& Rock, B.N. (1985). Imaging spectrometry for Earth remote sensing. Science 228:1147-1153. doi: $10.1126 /$ science. 228.4704 .1147 
Rubén Martínez-Barbáchano, Gustavo Adolfo Solis-Miranda. Caracterización Espectral y Detección de

Flecha Seca en Palma Africana en Puntarenas, Costa Rica

James-Jayaselas, H.A., Mat-Nawi, N., Wan-Ismail, W.I., Mohamed-Shariff, A.R. Juva-Rajah, V. \& Arulandoo, X. (2017). Application of spectroscopy for nutrient prediction of oil palm. Journal of Experimental Agriculture International, 15(3), 1-9. Recuperado de http:// www.journalrepository.org/media/journals/JEAI_51/2017/Feb/Jayaselan1532017JEAI31502.pdf

Mather, P. (2004). Computer processing of remotely-sensed images. $2^{\text {nd }}$ ed. John Wiley \& Sons, GBR.

Ramsay, J. and Silverman, B.W. (2005). Functional data analysis. 2ed. Berlin, GBR: Springer.

Suárez, L., Zarco-Tejada, P.J., González-Dugo, V., Berni, J. A. J. y Fereres, E. (2009). Detección de estrés hídrico y calidad de fruto en cultivos mediante el índice PRI a partir de imágenes de alta resolución espacial. Agua y desarrollo sostenible. (29-32) En: S. MontecinosAranda, y L. Fernández-Formos, editores, XIII Congreso de la Asociación Española de Teledetección. Asociación Española de Teledetección, 7 Madrid, ESP. 